\title{
Aspectos produtivos e nutricionais de cereais de inverno em regimes de corte para ensilagem
}

Mattos Leao, G.F. ${ }^{1}$; Jobim, C.C. ${ }^{1}$; Neumann, M. ${ }^{2}$; dos Santos, S.K. ${ }^{3}$; Horst, E.H. ${ }^{4}$ e dos Santos, L.C. ${ }^{2}$

\author{
IUniversidade Estadual de Maringá. Brasil. \\ 2Universidade Estadual do Centro Oeste. Brasil. \\ 3Pontifícia Universidade Católica do Paraná (PUCPR/PPGCA). Brasil. \\ ${ }^{4}$ Universidade Estadual de Londrina. Brasil.
}

\section{PALAVRAS CHAVE ADICIONAIS}

Cevada.

FDA.

Morfologia

NDT.

Trigo.

Triticale.

\section{RESUMO}

O objetivo do estudo foi avaliar o efeito de três regimes de cortes em estádio vegetativo (Sem corte; um corte e dois cortes), sobre os aspectos produtivos e nutricionais de cinco cereais de inverno, colhidos para produção de silagem. Os cereais usados foram o trigo (Triticum aestivum cv. BRS Gralha Azul), cevada (Hordeum vulgare cv. BRS Brau), aveia branca (Avena sativa cv. URS Guará), aveia preta (Avena strigosa cv. Embrapa 139) e triticale (X Triticosecale cv. IPR 11). Para a massa de forragem seca total, o aumento no número de cortes gerou redução na produção de todos os cereais. O triticale apresentou a maior estabilidade produtiva, uma vez que não houve diferença $(P>0,05)$ para o regime sem corte (12.317 kg MS/ha) e com um corte (11.944 kg MS/ha). $O$ regime de cortes influenciou os componentes morfológicos, pois houve redução das porcentagens de colmo e folha e aumentou a porcentagem de espiga e a quantidade de folhas senescentes em relação as folhas totais. Os teores de NDT não foram influenciados negativamente pelos regimes de corte, com exceção da aveia branca. Dos cereais avaliados, a cevada apresentou menores valores $(\mathrm{P}<0,05)$ de FDA $(333,5 ; 359,2$ e $314,2 \mathrm{~g} \mathrm{~kg} / \mathrm{MS})$ e maiores valores de NDT no momento da ensilagem, independente do regime de corte. Conclui-se que o uso do triticale em regime de um corte no estádio vegetativo, pode ser recomendado para produção de silagem.

\section{Production and nutritional aspects of winter cereals for silage cutting schemes}

\section{SUMMARY}

\section{AdDITIONAL KEYWORDS}

Barley.

ADF.

Morphology.

TDN.

Wheat.

Triticale.

\section{INFORMATION}

\section{Cronología del artíiculo.}

Recibido/Received: 22.05.2017

Aceptado/Accepted: 24.03.2019

On-line: 07.04 .2019

Correspondencia a los autores/Contact e-mail:

gfleao@hotmail.com
The objective of this study was to evaluate the effect of three vegetative stage cuts schemes (Without cut; one cut and two cuts), production and nutritional aspects of five winter cereals, harvested for silage production. Cereals used were the wheat (Triticum aestivum cv. BRS Blue Jay), barley (Hordeum vulgare CV. BRS Brau), oats (Avena sativa cv URS Guará), black oats (Avena strigosa cv. Embrapa 139) and triticale (X Triticosecale cv. IPR 11 ). For the mass of total dry forage, the increase in the number of cuts generated reduction in production for all cereals. The triticale presented the greatest productive stability, since there were no differences $(P>0.05)$ for the blunt $(12,317 \mathrm{~kg} \mathrm{DM} / \mathrm{ha})$ and with a cut $(11,944 \mathrm{~kg} \mathrm{DM} / \mathrm{ha})$. The scheme of cuts influenced the morphological components, because there was a reduction of the culm and leaf percentages and increased the percentage of cob and the amount of senescent leaves towards the leaves. The TDN levels were not influenced negatively by cutting regimes, with the exception of white oats. For cereals, barley evaluated presented minor values $(P<0.05)$ of ADF $(333.5 ; 359.2$ and $314.2 \mathrm{~g} / \mathrm{kg}$ DM) and higher values of TDN at the time, independent of the silage cutting regime. Triticale can be used in a vegetative stage and silage production.

\section{INTRODUÇÃO}

Dentro do contexto do Sul do Brasil, uma alternativa para potencializar o uso de recursos como a terra, infraestrutura e mão de obra voltada para a produção de ruminantes seria a utilização de cereais de inverno para a produção de silagem (Lehmen et al., 2014, p. 1180-1185).

No Brasil, o uso destas silagens de cereais de inverno ainda não é representativo, comparando com outros países. Na Europa seu uso passou de "cultura esporádica" para "cultura de base" com o passar dos 
anos pelo seu excelente valor nutricional e sua alta versatilidade de uso (Bumbieris Jr et al., 2011, p. 39-71).

Devido a estas características, despertou-se o interesse do desenvolvimento de diferentes estratégias para explorar com mais eficiência os cereais de inverno. Um exemplo de estratégia que eventualmente poderia ser utilizada seria associar cortes no período vegetativo, com posterior diferimento da área para produção de silagem (Meinerz et al., 2011, p. 2097-2104).

A estratégia foi desenvolvida pelo fato de que, especialmente a aveia branca, a aveia preta e o trigo, que possuem porte alto, tem a probabilidade de acamamento reduzida, além do maior potencial de consumo e valor nutricional destes materiais no estádio vegetativo. No entanto, a utilização de um número excessivo de cortes desses cereais no estádio vegetativo, pode gerar impacto negativo para os aspectos produtivos e nutricionais para ensilagem (Meinerz et al., 2011, p. 2097-2104). Pode também implicar em menor porção de grãos para venda ou como participante na ensilagem.

Além disso, nem todo cereal de inverno responde da mesma maneira a esta estratégia de cortes. Portanto, faz-se necessário pesquisas para determinar a melhor estratégia de uso de cada cereal, em relação ao número de cortes adequados antes da colheita para ensilagem. Tal fato é relevante com vistas a equilibrar os aspectos produtivos e nutricionais dos cereais, para que seja possível gerar recomendações mais assertivas dentro do contexto de planejamento forrageiro na propriedade.

Desta forma, o objetivo do estudo foi avaliar o efeito do regime de cortes sobre os aspectos produtivos e nutricionais de cereais de inverno visando a produção de silagem.

\section{MATERIAL E MÉTODOS}

O experimento foi conduzido no localizado no município de Guarapuava - PR, Brasil, situado na zona subtropical do Paraná, sob as coordenadas geográficas $25^{\circ} 23^{\prime} 02^{\prime \prime}$ de latitude sul e $51^{\circ} 29^{\prime} 43^{\prime \prime}$ de longitude oeste e $1.026 \mathrm{~m}$ de altitude. O clima da região segundo a classificação de Köppen é o Cfb (Subtropical mesotérmico úmido), com verões amenos e inverno moderado, sem estação seca definida e com geadas severas. A precipitação média anual é de $1944 \mathrm{~mm}$, temperatura média mínima anual de $12,7^{\circ} \mathrm{C}$, temperatura média máxima anual de $23,5^{\circ} \mathrm{C}$ e umidade relativa do ar de $77,9 \%$ (Iapar, 2000).

O solo da área experimental é classificado como Latossolo Bruno Típico e em ocasião antecipada ao plantio apresentou as seguintes características químicas (perfil de 0 a $20 \mathrm{~cm}$ ): $\mathrm{pH} \mathrm{CaCl} \mathrm{C}_{2}$,01M: 4,7; P: 1,1 mg $\mathrm{dm}^{-3} ; \mathrm{K}^{+}: 0,2 \mathrm{cmol}_{\mathrm{c}} \mathrm{dm}^{-3} ; \mathrm{MO}: 2,62 \% ; \mathrm{Al}^{3+}: 0,0 \mathrm{cmol}_{\mathrm{c}} \mathrm{dm}^{-}$ 3; $\mathrm{H}^{+}+\mathrm{Al}^{3+}: 5,2 \mathrm{cmol}_{\mathrm{c}} \mathrm{dm}^{-3} ; \mathrm{Ca}^{2+}: 5,0 \mathrm{cmol}_{\mathrm{c}} \mathrm{dm}^{-3} ; \mathrm{Mg}^{2+}: 5,0$ $\mathrm{cmol}_{\mathrm{c}} \mathrm{dm}^{-3}$ e saturação de bases: $67,3 \%$. Para correção do $\mathrm{pH}$ do solo foi utilizado calcário conforme a recomendação de um engenheiro agrônomo.

Como material experimental utilizou-se o trigo (Triticum aestioum cv. BRS Gralha Azul), cevada (Hordeum vulgare cv. BRS Brau), aveia branca (Avena sativa cv. URS Guará), aveia preta (Avena strigosa cv. Embrapa 139 ) e triticale ( $X$ Triticosecale cv. IPR 11), e estes materiais foram submetidos a três regimes de corte: sendo uma área sem cortes (silagem exclusivo); com um corte; e com dois cortes em estádio vegetativo, totalizando 15 tratamentos. Após a realização dos cortes no estádio vegetativo dos cereais, as áreas foram vedadas visando a produção de silagem.

O campo experimental constituiu-se de uma área total de $225 \mathrm{~m}^{2}$, distribuída em 75 parcelas de $3 \mathrm{~m}^{2}$ cada (3m x 1m) com área útil de $1,60 \mathrm{~m}^{2}(1 \mathrm{~m} \times 1,6 \mathrm{~m})$ para as avaliações. Cada parcela representou uma unidade experimental (repetição). A semeadura do campo experimental ocorreu no dia 03 de junho de 2014 em sistema de plantio direto, com uso de semeadora modelo Semeato SHM 15/17, empregando-se a mesma densidade para todas as culturas. No plantio o espaçamento entre linhas foi de $0,17 \mathrm{~m}$, a profundidade de semeadura foi de $0,04 \mathrm{~m}$ com distribuição de 400 sementes por $\mathrm{m}^{2}$.

Por ocasião da semeadura, realizou-se a adubação de base com $300 \mathrm{~kg} \mathrm{ha}^{-1}$ do fertilizante formulado 0830-20 (N- $\left.\mathrm{P}_{2} \mathrm{O}_{5}-\mathrm{K}_{2} \mathrm{O}\right)$, respeitando recomendações da comissão de fertilidade do solo de Santa Catarina e Rio Grande do Sul (2004, p. 400). A adubação nitrogenada de cobertura foi feita em uma única aplicação, 30 dias após o plantio com $196 \mathrm{~kg} \mathrm{ha}^{-1}$ de uréia (46\%-00-00), o que totalizou $90 \mathrm{~kg}^{-1}$ de nitrogênio. As plantas daninhas foram controladas quimicamente com herbicidas, primeiramente na dessecação da área experimental, realizada no dia 10 de maio de 2014, utilizando-se herbicida a base de Glifosate (produto comercial Roundup WG ${ }^{\circledR}: 3,0 \mathrm{~kg} \mathrm{ha}^{-1}$ ).

No manejo da cultura, 30 dias após o plantio foi efetuada a aplicação do herbicida a base de metsulfuron-metyl (produto comercial Ally ${ }^{\circledR}: 6,6 \mathrm{~g} \mathrm{ha}^{-1}$ ). O controle de pragas foi realizado até 30 dias após a emergência das plantas, de acordo com avaliações de campo, indicando o ponto de dano econômico, sendo utilizado o inseticida a base de Imidacloprido + Beta ciflutrina (produto comercial Connect ${ }^{\circledR}: 500 \mathrm{~mL} \mathrm{ha}^{-1}$ ). No controle preventivo de doenças fúngicas foi necessário o emprego de fungicida a base de propiconazol (produto comercial Tilt ${ }^{\circledR}: 750 \mathrm{~mL} \mathrm{ha}^{-1}$ ). Todas as aplicações químicas foram realizadas mediante laudo técnico das lavouras.

O corte das plantas foi realizado de forma manual com o auxílio de foices na área útil de cada parcela $\left(1,60 \mathrm{~m}^{2}\right)$, nas quais foram coletadas cinco amostras aleatórias e representativas (quadro de 0,25 $\mathrm{m}^{2}$ ) da área de cada tratamento. Após os cortes, os materiais foram pesados e uma amostra de $500 \mathrm{~g}$ de plantas de cada parcela foi posteriormente condicionada em estufa de ar forçado regulada para temperatura de $55^{\circ} \mathrm{C}$, por 72 horas para a determinação dos teores de matéria seca da planta inteira conforme Silva \& Queiróz (2009, p. 235) e consequentemente foi quantificado a produção de massa de forragem seca (kg MS/ha).

O momento dos cortes, no estádio vegetativo, tanto para os tratamentos submetidos a um e dois cortes, seguiram recomendações de Fontanelli et al. (2009, p. 
2116-2120), ou seja, os cortes foram realizados quando as plantas, em cada tratamento, atingiram altura média de $30 \mathrm{~cm}$, sendo estas rebaixadas a $8 \mathrm{~cm}$ da superfície do solo. O momento do corte para ensilagem se deu quando as plantas atingiram o estádio de grão farináceo mole.

No momento da ensilagem foram coletadas duas amostras homogêneas de $500 \mathrm{~g}$ de cada cereal para cada tratamento, sendo a primeira para a determinação de MS e posteriormente encaminhada para as análises químicas conforme Silva \& Queiróz (2009, p. 235). A segunda amostra foi utilizada para a avaliação dos componentes estruturais da planta, sendo segmentados em colmo, folhas totais (folhas verdes + folhas senescentes) e espiga e posteriormente conduzidos a estufa de circulação de ar forçado visando à composição do material em porcentagem da MS. A partir destes componentes foi possível mensurar a relação folha/ colmo e também a porcentagem de folhas senescentes em relação às folhas totais (S/FT). Além disto, também no momento da ensilagem foi determinada a altura médias das plantas através de medição com fita graduada.

As amostras pré-secas dos cereais de inverno, tanto em estádio vegetativo como no momento da ensilagem, foram moídos a $1 \mathrm{~mm}$ em moinho tipo "Willey", onde sequencialmente determinou-se a matéria seca total em estufa a $105^{\circ} \mathrm{C}$ por 16 horas (Silva \& Queiroz, 2009 , p. 235), proteína bruta (PB) pelo método micro Kjeldahl, matéria mineral (MM) por incineração a $550^{\circ} \mathrm{C}$ ( 4 horas). Foram determinados os teores de fibra em detergente neutro (FDN), conforme Van Soest et al. (1991), Robertson \& Lewis (1991, p. 3583-3597), utilizando-se $\alpha$ amilase termoestável (Termamyl 120L, Novozymes Latin América Ltda.), fibra em detergente ácido (FDA) segundo Goering \& Van Soest (1970, p. 379.) e os teores de hemicelulose por diferença (hemicelulose $=$ FDN - FDA) seguindo metodologia proposta por Silva \& Queiroz (2009, p. 235). O teor de nutrientes digestíveis totais (NDT) na forragem foi estimado segundo a equação NDT $=74,49-0,5635^{*} \mathrm{FDA}\left(\mathrm{r}^{2}=0,84\right)$, descrita por Cappelle et al. (2001, p. 1837-1856) para volumosos.

O delineamento experimental empregado foi de blocos ao acaso em arranjo fatorial composto por 15 tratamentos sendo cinco espécies de cereais de inverno (Trigo, Triticale, Cevada, Aveia Branca e Aveia Preta) associado a três regimes de corte prévios a colheita para ensilagem (sem cortes; com um corte; e com dois cortes) e cinco repetições. Os resultados obtidos foram submetidos à análise de variância e comparados utilizando o teste Tukey ao nível de $5 \%$ de significância por intermédio do programa estatístico SAS (2015, p. 943).

\section{RESULTADOS E DISCUSSÕES}

Houve interação significativa $(\mathrm{P}<0,05)$ entre os cereais de inverno e os regimes de corte para a produção de massa de forragem seca (Tabela 1). Primeiro com relação aos cortes no período vegetativo, nota-se que somente para o regime com um corte, houve diferença $(\mathrm{P}<0,05)$ entre os cereais, enquanto que isto não ocorreu para o regime com dois cortes, tanto no $1^{\circ}$ como no $2^{\circ}$ corte.
Avaliando o rendimento de forragem no regime com um corte, observa-se que a aveia preta foi superior somente em relação à cevada, não diferindo dos demais cereais. Os resultados encontrados para a aveia preta foram superiores aos obtidos por Fontanelli et al. (2009, p. 2116-2120), (720 versus $622 \mathrm{~kg}$ de MS/ha). Todavia, em comparação com os dados destes mesmos autores, mas com relação às demais culturas avaliadas, as produções foram inferiores, sendo que a cevada foi o que apresentou maior diferença produtiva (400 versus $936 \mathrm{~kg}$ de MS/ha). A aveia preta é reconhecidamente um cereal mais produtivo e menos susceptível a doenças em relação à cevada (Carvalho et al., 2013, p. 494-537), o que pode justificar a maior produção de forragem encontrada, embora isto não tenha sido observado para o regime com dois cortes.

Vale ressaltar que é possível notar, em confronto com a literatura (Bortolini et al., 2004, p. 45-50), que as produtividades observadas no estádio vegetativo dos cereais de inverno possui grande amplitude, sendo que isto pode ser atribuído a fatores como: cultivar, condições edafo-climáticas, condução da lavoura experimental, teor de MS no momento do corte e manejo ao corte.

$\mathrm{Na}$ ensilagem, constatou-se que para o regime sem cortes em estádio vegetativo, a maior produção de massa de forragem seca foi para o triticale e o trigo (12.317 e $11.335 \mathrm{~kg}$ MS/ha). Tais resultados foram superiores aos encontrados por Fontanelli et al. (2009, p. 2116-2120), Meinerz et al. (2011, p. 2097-2104) e Lehmen et al. (2014, p. 1180-1185), os quais observaram, para o triticale e o trigo, as produções de 5.234 e $5.096 \mathrm{~kg}$ MS/ha; 9.267 e 8.262 kg MS/ha; 10.071 e 9.812 kg MS/ ha respectivamente. É importante destacar que a aveia branca e a aveia preta, mesmo sendo inferiores ao triticale e ao trigo, também mostraram boas produções de MS (9.443 e $9.752 \mathrm{~kg}$ MS/ha), sendo semelhantes aos resultados de Lehmen et al. (2014, p. 1180-1185) (9.144 e $9.552 \mathrm{~kg}$ MS/ha).

Para os regimes com um e dois cortes, para todos os cereais avaliados, observou-se decréscimo na produção de massa de forragem seca disponível para ensilagem, e consequentemente redução na massa de forragem seca total em relação ao regime sem cortes no estádio vegetativo (Tabela 1 e Figura 1). Tal efeito de decréscimo produtivo é justificado por Bortolini et al. (2004, p. 45-50), que indicam que o sistema de desfolha provoca estresse na planta pela remoção da área foliar. Quanto mais desfolhas, maior remoção da área foliar e consumo de nutrientes de reserva. Com isto, diminui-se a área fotossinteticamente ativa, o que, por conseguinte, implica em menor rendimento da forragem (Harrison et al., 2011, p. 930-946).

A exceção entre os cereais avaliados foi o triticale, pois apresentou boa estabilidade produtiva, sendo que não apresentou diferença significativa entre os regimes sem e com um corte, demonstrando decréscimo produtivo de apenas 7,96\% (Figura 1). Com o regime de dois cortes, a produtividade foi evidentemente inferior, sendo 51,97\% menor em relação ao sistema sem cortes, embora sendo mais produtivo entre todos os cereais avaliados. 
Tabela I. Produção de massa de forragem seca de cereais de inverno submetidos a diferentes regimes de cortes em estádio vegetativo, e posterior diferimento para produção de silagem em estádio de grão farináceo mole (Dry matter production of winter cereals subject to different pattern of cuts in a vegetative stage, and subsequent silage production in dough phonological stage).

\begin{tabular}{|c|c|c|c|c|c|c|}
\hline \multirow{2}{*}{ Regime de cortes } & \multicolumn{5}{|c|}{ Cereais de inverno } & \multirow[b]{2}{*}{ Valor de $\mathrm{F}$} \\
\hline & Trigo & Triticale & Cevada & Aveia Branca & Aveia Preta & \\
\hline \multicolumn{7}{|c|}{ Produção de massa de forragem seca (kg MS ha-1) } \\
\hline \multicolumn{7}{|c|}{ Sem cortes } \\
\hline Ensilagem/ Total & $11.335^{a}$ & $12.317^{a}$ & $6.929^{c}$ & $9.443^{b}$ & $9.752^{\mathrm{b}}$ & $<0,001$ \\
\hline \multicolumn{7}{|c|}{ Um corte } \\
\hline $1^{\circ}$ Corte & $528^{\mathrm{ab}}$ & $608^{\mathrm{ab}}$ & $400^{b}$ & $544^{\mathrm{ab}}$ & $720^{\mathrm{a}}$ & 0,0170 \\
\hline Ensilagem & $6.136^{\mathrm{b}}$ & $11.336^{\mathrm{a}}$ & $5.004^{c}$ & $5.716^{\mathrm{b}}$ & $6.029^{b}$ & $<0,001$ \\
\hline Total & $6.664^{\mathrm{b}}$ & $11.944^{a}$ & $5.404^{c}$ & $6.260^{\mathrm{b}}$ & $6.749^{b}$ & $<0,001$ \\
\hline \multicolumn{7}{|c|}{ Dois cortes } \\
\hline $1^{\circ}$ Corte & 576 & 656 & 592 & 640 & 576 & 0,8463 \\
\hline $2^{\circ}$ Corte & 944 & 896 & 768 & 736 & 800 & 0,4053 \\
\hline Ensilagem & $2.185^{c d}$ & $5.915^{a}$ & $4.047^{b}$ & $2.503^{c}$ & $2.091^{\mathrm{d}}$ & $<0,001$ \\
\hline Total & $3.705^{c}$ & $7.467^{a}$ & $5.407^{\mathrm{b}}$ & $3.879^{c}$ & $3.467^{c}$ & $<0,001$ \\
\hline
\end{tabular}

Médias seguidas de letras minúsculas na linha diferem entre si pelo teste Tukey a $5 \%$.

Esta alta produção pode ser atribuída ao fato do triticale ser um cereal advindo do cruzamento entre o trigo e o centeio, apresentando características positivas de ambos os cereais, sobretudo o potencial produtivo aliado a tolerância de crescimento sob diferentes formas de manejo (McGoverin et al., 2011, p. 1155-1165). Devido a estas características intrínsecas, seu uso em sistemas de duplo propósito, tanto visando produção de grãos como a produção de silagem é recomendado.

Outros fatores que impactaram na produção de massa de forragem seca dos cereais foram os componentes morfológicos e a altura de planta. Observa-se na
Tabela II que houve interação $(\mathrm{P}<0,05)$ entre os cereais de inverno e os regimes de corte.

A aveia preta apresentou as maiores proporções de colmo, independentemente do regime de corte, embora não diferindo da aveia branca nos regimes com um e dois cortes. Observou-se também que houve redução $(\mathrm{P}<0,05)$ da fração colmo a medida que se aumentou o número de cortes.

O componente folhas, por sua vez, também apresentou redução $(\mathrm{P}<0,05)$ com o aumento do número de cortes. Com relação aos cereais, a cevada apresentou as maiores porcentagens de folhas para o regime sem

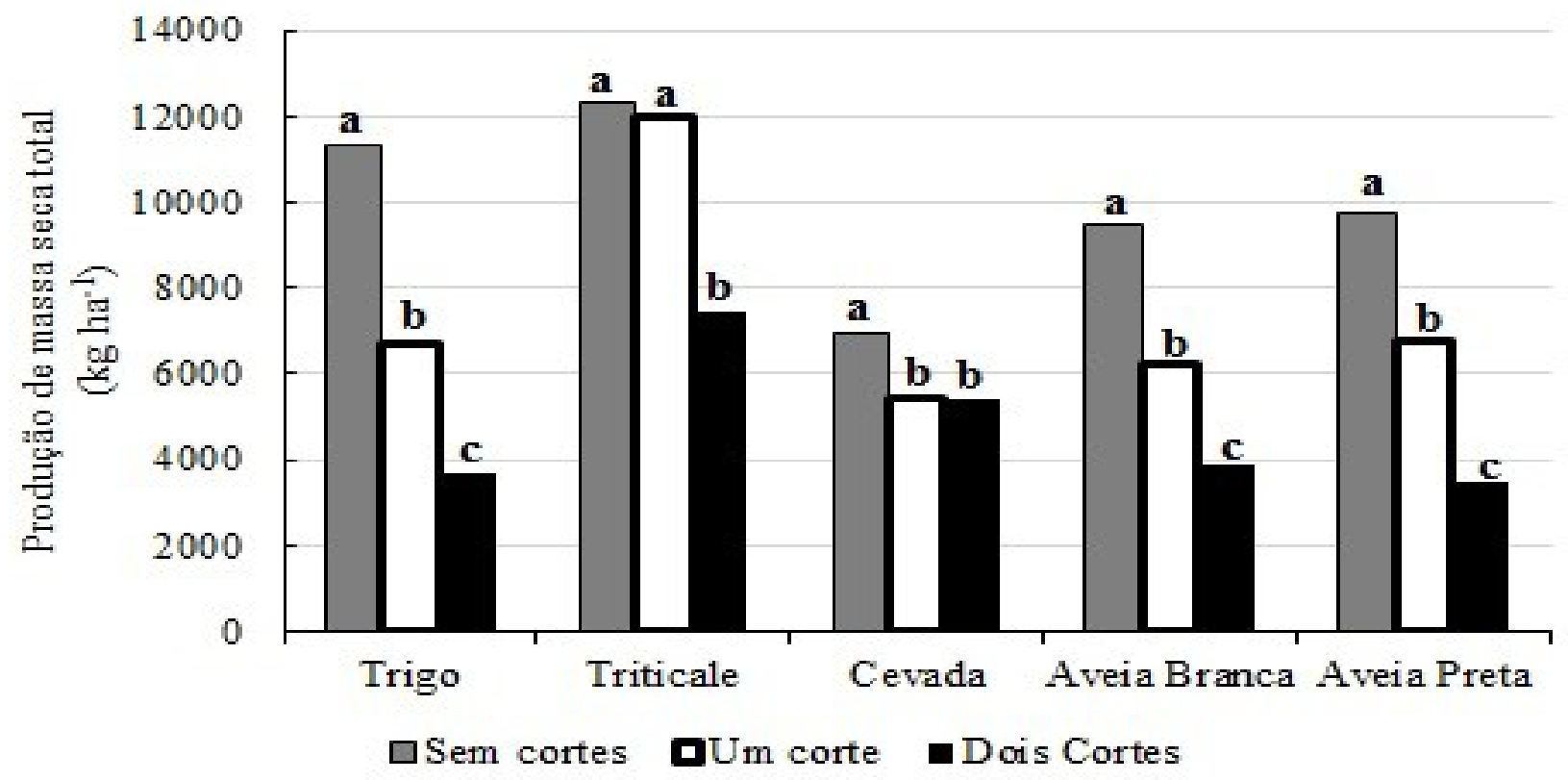

Figura 1. Produção de massa de seca total acumulada dos cereais de inverno de acordo com o regime de corte (Accumulated dry matter production of accumulated winter cereals according with the pattern of cuts). 
e com dois cortes, embora neste último não diferindo da aveia preta. Isto corroborou para que a cevada obtivesse as maiores razões folha/colmo, mesmo que para o regime com um corte não tenha sido encontrada diferença significativa. Em relação ao regime sem cortes, houve redução $(\mathrm{P}<0,05)$ somente para a aveia branca neste quesito.

A porcentagem de espiga aumentou $(\mathrm{P}<0,05)$ com o aumento do número de cortes para todos os cereais avaliados. Para os cereais, a aveia preta foi o destaque negativo, pois apresentou as menores participações deste componente em relação a sua MS total.

A proporção de folhas senescentes em relação às folhas totais (FS/FT) apresentou aumento significativo em relação ao número de cortes, com exceção do trigo que não apresentou diferença estatística. O trigo, a cevada e a aveia preta apresentaram as maiores quantidades de material senescente, mesmo que não tenha sido observada diferença $(P>0,05)$ entre os materiais no regime com dois cortes. Na avaliação da altura de

Tabela II. Composição morfológica, no momento da ensilagem, de cereais de inverno submetidos a diferentes regimes de corte (Morphological composition at ensiling time of winter cereals subjected to different cutting regimes).

\begin{tabular}{|c|c|c|c|}
\hline \multirow{2}{*}{ Cereais de inverno } & \multicolumn{3}{|c|}{ Regimes de corte } \\
\hline & Sem cortes & Um corte & Dois cortes \\
\hline \multicolumn{4}{|c|}{ Colmo (g kg MS $\left.{ }^{-1}\right)$} \\
\hline Trigo & $414,67^{\mathrm{CA}}$ & $360,00^{\mathrm{bAB}}$ & $296,67^{\mathrm{CB}}$ \\
\hline Triticale & $513,33^{\mathrm{bA}}$ & $402,33^{\mathrm{bB}}$ & $379,67^{\mathrm{bB}}$ \\
\hline Cevada & $323,33^{\mathrm{dA}}$ & $350,00^{\mathrm{bA}}$ & $190,00^{\mathrm{dB}}$ \\
\hline Aveia Branca & $493,33^{\mathrm{bc} A \mathrm{~B}}$ & $570,00^{\mathrm{aA}}$ & $453,33^{\mathrm{aB}}$ \\
\hline Aveia Preta & $616,66^{\mathrm{aA}}$ & $590,00^{\mathrm{aA}}$ & $480,00^{\mathrm{aB}}$ \\
\hline \multicolumn{4}{|c|}{ Folha $\left(\mathrm{g} \mathrm{kg} \mathrm{MS}^{-1}\right)$} \\
\hline Trigo & $236,33^{\mathrm{bA}}$ & $140,00^{\mathrm{AB}}$ & $100,00^{\mathrm{bB}}$ \\
\hline Triticale & $196,67^{b}$ & 167,67 & $100,00^{b}$ \\
\hline Cevada & $396,67^{\mathrm{aA}}$ & $223,33^{B}$ & $223,67^{\text {ав }}$ \\
\hline Aveia Branca & $180,00^{\mathrm{bA}}$ & $180,00^{\mathrm{A}}$ & $126,67^{\mathrm{bB}}$ \\
\hline Aveia Preta & $210,34^{b}$ & 210,00 & $176,00^{\mathrm{ab}}$ \\
\hline \multicolumn{4}{|c|}{ Espiga $\left(\mathrm{g} \mathrm{kg} \mathrm{MS}^{-1}\right)$} \\
\hline Trigo & $350,00^{\mathrm{aB}}$ & $500,00^{\mathrm{aAB}}$ & $603,33^{\mathrm{aA}}$ \\
\hline Triticale & $290,00^{\mathrm{aB}}$ & $430,00^{\mathrm{aA}}$ & $520,33^{\mathrm{abA}}$ \\
\hline Cevada & $280,00^{\mathrm{ac}}$ & $426,67^{\mathrm{aB}}$ & $586,33^{\mathrm{aA}}$ \\
\hline Aveia Branca & $326,67^{\text {аАв }}$ & $250,00^{\mathrm{bB}}$ & $420,00^{\mathrm{bcA}}$ \\
\hline Aveia Preta & $173,00^{\mathrm{bB}}$ & $200,00^{\mathrm{bB}}$ & $344,00^{\mathrm{cA}}$ \\
\hline \multicolumn{4}{|c|}{ Folha/Colmo } \\
\hline Trigo & $0,56^{b}$ & 0,39 & $0,33^{b}$ \\
\hline Triticale & $0,38^{b}$ & 0,42 & $0,26^{b}$ \\
\hline Cevada & $1,23^{\mathrm{a}}$ & 0,64 & $1,20^{\mathrm{a}}$ \\
\hline Aveia Branca & $0,37^{\mathrm{bA}}$ & $0,31^{\mathrm{AB}}$ & $0,27^{\mathrm{bB}}$ \\
\hline Aveia Preta & $0,34^{b}$ & 0,35 & $0,36^{b}$ \\
\hline \multicolumn{4}{|c|}{$\mathrm{FS} / \mathrm{FT}(\%)$} \\
\hline Trigo & $61,00^{\mathrm{a}}$ & $78,33^{\mathrm{ab}}$ & 100,00 \\
\hline Triticale & $11,00^{\mathrm{cB}}$ & $28,33^{\mathrm{cB}}$ & $94,33^{A}$ \\
\hline Cevada & $35,66^{\mathrm{abcc}}$ & $72,00^{\mathrm{abB}}$ & $100,00^{A}$ \\
\hline Aveia Branca & $21,66^{\mathrm{bcc}}$ & $53,33^{\mathrm{bcB}}$ & $91,66^{A}$ \\
\hline Aveia Preta & $43,33^{\mathrm{abB}}$ & $100,00^{\mathrm{aA}}$ & $100,00^{\mathrm{A}}$ \\
\hline \multicolumn{4}{|c|}{ Altura de Planta (m) } \\
\hline Trigo & $0,80^{\mathrm{dA}}$ & $0,71^{\mathrm{dB}}$ & $0,63^{d c}$ \\
\hline Triticale & $1,05^{\mathrm{cA}}$ & $0,99^{\mathrm{cA}}$ & $0,90^{\mathrm{cB}}$ \\
\hline Cevada & $0,59^{\text {ев }}$ & $0,68^{\mathrm{eA}}$ & $0,61^{\mathrm{dB}}$ \\
\hline Aveia Branca & $1,12^{\mathrm{b}}$ & $1,20^{\mathrm{b}}$ & $1,12^{b}$ \\
\hline Aveia Preta & $1,46^{\mathrm{aA}}$ & $1,38^{\mathrm{aA}}$ & $1,29^{a B}$ \\
\hline
\end{tabular}

FS/FT: Porcentagem de folhas senescentes em relação as folhas totais. Médias seguidas de letras minúsculas na coluna e maiúsculas na linha diferem entre si pelo teste Tukey a $5 \%$. 

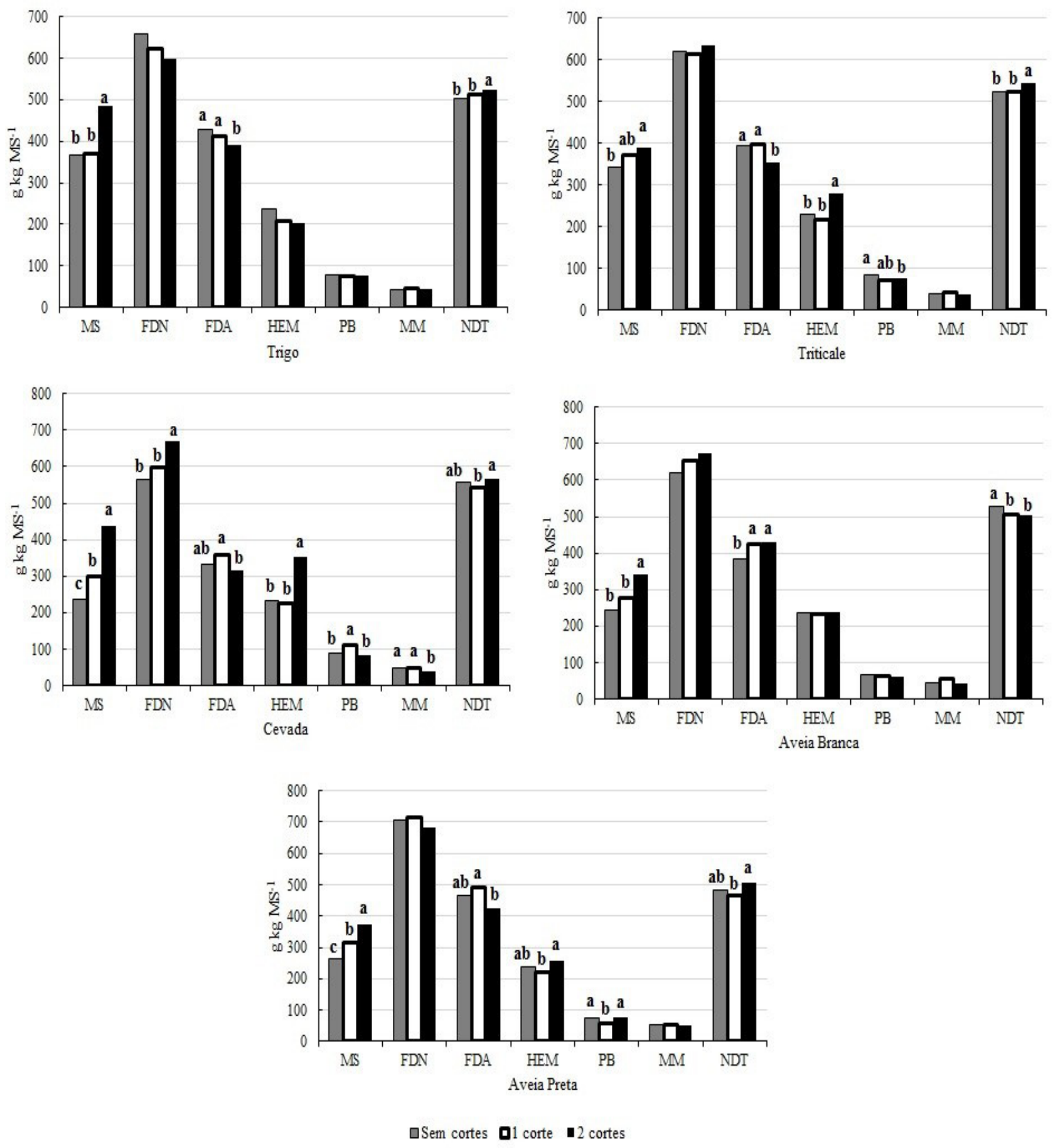

Figura 2. Comportamento dos parâmetros nutricionais de cereais de inverno no momento da ensilagem de acordo com os regimes de corte (Behavior of Nutritional parameters of cereals at ensiling time winter according to cutting regimes).

planta, pode-se inferir que a aveia preta foi a que apresentou maior altura, independentemente do número de cortes em que foi submetido. E na avaliação entre os regimes de corte, foi possível observar redução significativa da altura com o aumento do número de cortes, com exceção da aveia branca.

Os comportamentos dos componentes morfológicos supracitados estão intimamente ligados ao processo de corte. $\mathrm{O}$ corte reduz o índice foliar da planta, levando a redução na porcentagem de folhas. Esta redução neste componente implicaria diretamente na taxa de fotos- síntese, reduzindo a quantidade de fotoassimilados disponíveis e aumentando a necessidade para mobilização de reservas, o que substancialmente reduziria a proporção de colmos e consequentemente a altura dos cereais, impactando inclusive em menores produções de MS (Taiz \& Zeiger, 2009, p. 819).

Todavia, a maior quantidade de espiga encontrada é reflexo da concentração deste componente em relação aos demais, pois com o aumento do número de cortes há prolongamento do ciclo fenológico dos cereais, acarretando um aumento nos teores de MS e na 
proporção de material senescente, fatos que ocorreram no presente trabalho. Corroborando com isto, Meinerz et al. (2011, p. 2097-2104), avaliando cereais de inverno em regime de cortes, também observaram aumento no teor de MS e de material senescente dos materiais no momento da ensilagem, o que foi correlacionados com maior proporção de espigas. Para os autores isto também implicou com as menores produções de massa de forragem seca, o que também está de acordo com os achados do presente trabalho.

A redução da altura da planta em cereais de inverno é benéfica no sentido da diminuição ou eliminação do acamamento, pela redução no comprimento de colmos e produção de espigas menores (Bortolini et al., 2004, p. 45-50). Isto é essencial, sobretudo em locais de elevadas altitudes e com ventos fortes como a região de Guarapuava (PR), pois a produtividade destes cereais e os processos operacionais podem ser comprometidos pelo acamamento das plantas.

Por outro lado, a redução na produção de MS e de grãos pode comprometer a produção de silagem em si, pela menor quantidade de material disponível para os microrganismos no silo, o que, por conseguinte, pode comprometer a qualidade de conservação (Jobim \& Nussio, 2013, p. 649-660).

Os aumentos nos percentuais de material senescente, por sua vez, geram incremento de materiais pouco digestíveis, como a celulose ou indigestíveis, como a lignina, reduzindo o valor nutricional e o potencial de consumo das silagens (Nascimento Júnior et al., 2013, p. 409-424). Porém, os cereais mostraram respostas distintas relacionando o regime de corte com o valor nutricional.

Com relação ao valor nutricional, pode-se observar que houve interação $(\mathrm{P}<0,05)$ entre os cereais de inverno e os regimes de corte (Tabela 3). O trigo foi o que apresentou os maiores valores para o teor de MS, independendo do número de cortes a que foi submetido, não diferindo do triticale para o regime sem e com um corte. Esta diferença entre os teores de MS pode ser explicada pelas distinções de ciclo fenológico dos materiais, sendo esta uma característica genética intrínseca de cada cereal.

A aveia preta foi o cereal que apresentou maior teor de fibra em detergente neutro (FDN) e fibra em detergente ácido (FDA), independentemente do regime de corte, embora não tenha sido observada diferença para a cevada (FDN) e aveia branca (FDN e FDA).

A aveia preta possui esta característica de alto teor de FDN e de FDA em virtude de sua grande rusticidade e maior resistência a doenças foliares (Carvalho et al., 2013, p. 494-537). Em contraste, apesar destas vantagens, nota-se que a FDN tem efeito inversamente proporcional sobre o consumo, e a FDA sobre a digestibilidade da matéria seca da forragem. Ou seja, com o aumento destas frações há decréscimo significativo da digestibilidade do alimento, além de redução no consumo voluntário, uma vez que estes carboidratos fibrosos exigem maior dispêndio de tempo para ruminação, além de gerarem maior efeito de enchimento (Nussio et al. 2011; Campos; Lima, 2011, p. 193-238).
Isto caracteriza menor valor nutricional para a aveia preta em relação aos demais.

Para hemicelulose (HEM) não foi encontrado diferença $(P>0,05)$ para os regimes sem e com um corte. Porém, para o regime com dois cortes, a cevada apresentou o maior valor entre os cereais. Além disto, para proteína bruta, a cevada apresentou os maiores valores, independendo do número de cortes, mesmo que não diferindo da aveia preta, trigo e triticale para o regime com dois cortes.

A cevada apresenta estas características em virtude de um programa de melhoramento intenso, no qual foram descobertos genes que influenciam tanto a quantidade como a qualidade da proteína deste cereal (Bumbieris Jr. et al., 2011, p. 39-71). Outro detalhe importante relativo a cevada, é que foi o material que apresentou maiores teores de nutrientes digestíveis totais (NDT), embora não diferindo $(\mathrm{P}>0,05)$ do triticale para o regime com um corte. Isto, segundo Amanullah et al. (2014, p. 511-517), é devido ao seu alto teor de carboidratos fermentescíveis, além da baixa proporção de carboidratos fibrosos. Tal fato pode ser justificado pela maior quantidade de folhas e menores proporções de colmo conforme discutido anteriormente. Com relação aos regimes de corte, para todos os cereais, foi possível observar aumento característico do teor de MS (Figura 2).

Conforme supracitado, este aumento da MS advém do maior ciclo que estes cereais possuem, sendo um efeito direto do corte. Outro ponto possível de ser observado foi a redução nos teores de FDA dos cereais, com exceção da aveia branca, o que culminou em aumento nos níveis estimados de NDT. Isto claramente é reflexo da menor quantidade de colmo e consequente aumento da componente espiga, contribuindo pela menor participação de componentes fibrosos, o que consequentemente melhora o valor nutricional dos cereais.

Houve incremento significativo do FDN somente para a cevada, uma vez que uma planta mais velha possui maior espessamento e lignificação da parede celular, podendo gerar tais alterações (Carvalho \& Pires, 2008, p. 13-28). Um detalhe interessante foi que ocorreu um aumento significativo nos teores de HEM para o triticale, para a cevada e para a aveia preta, e pode ser explicado também pela menor proporção de colmo e maior de espigas.

\section{CONCLUSÃO}

O aumento no número de cortes no estádio vegetativo implicou em redução dos aspectos produtivos dos cereais de inverno, enquanto que os aspectos nutricionais não foram influenciados negativamente, com exceção da aveia branca. Dentre os cereais de inverno avaliados, o triticale foi o cereal que apresentou maior potencial para produção de forragem em regimes de corte, podendo ser indicado um corte no estádio vegetativo e posterior ensilagem sem prejuízos significativos aos aspectos produtivos e nutricionais. $\mathrm{Na}$ avaliação dos aspectos nutricionais, houve diferenças entre os cereais para cada regime de corte, mas pode-se destacar a cevada como o cereal com maiores valores 
de NDT, embora não tenha diferido do triticale para o regime de um corte.

\section{REFERÊNCIAS}

Amanullah, SM, Kim, DH, Lee, HJ, Joo, YH, Kim, SB \& Kim, SC, 2014, 'Effects of microbial additives on chemical composition and fermentation characteristics of barley silage', Asian Australian Journal of Animal Science, vol. 27, $n^{\circ}$. 4, pp. 511-517.

Bortolini, PC, Sandini, I, Carvalho, CF \& Moraes, A, 2004, 'Cereais de inverno submetidos ao corte no sistema de duplo propósito', Revista Brasileira de Zootecnia, vol. 33, $n^{\circ}$. 1, pp. 45-50.

Bumbieris Jr, JR, Oliveira, VH, Jobim, CC, Barbosa, MAAF, Castro, LM, \& Barrero, RP, 2011, 'Perspectivas para uso de silagem de cereais de inverno no Brasil', In: IV Simpósio de produção e utilização de forragens conservadas, ed. 4, Maringá, PR, pp. 39-71.

Cappelle, ER, Valadares Filho, SC, Silva, JFC \& Cecon, PR, 2001, 'Estimativas do valor energético a partir de características químicas e bromatológicas dos alimentos 1', Revista Brasileira de Zootecnia, vol. $30, n^{\circ} .6$, pp. 1837-1856

Carvalho, GGP \& Pires, AJV, 2008, 'Organização dos tecidos de plantas forrageiras e suas implicações para os ruminantes', Archivos de Zootecnia, vol. 57, pp. 13-28.

Carvalho, PCF, Santos, DT, Gonçalves, EN, Moraes, A \& Nabinger, C, 2013, 'Forrageiras de clima temperado'. In: Plantas forrageiras, ed. 2, Viçosa, cap. 15, pp. 494-537.

Comissão de química e fertilidade do solo - CQFSRS/SC, 2004, 'Manual de adubação e calagem para os Estados do Rio Grande do Sul e de Santa Catarina', ed. 10, Porto Alegre, SBCS - Núcleo Regional Sul/ UFRGS, pp. 400

Fontanelli, RS, Fontanelli, RS, Santos, HP, Nascimento Júnior, A, Minella, E \& Caierão, E, 2009, 'Rendimento e valor nutritivo de cereais de inverno de duplo propósito: forragem verde e silagem ou grãos', Revista Brasileira de Zootecnia, vol. 38, n . 11, pp. 2116-2120.

Goering, HK \& Van Soest, PJ, 1970, 'Forage fiber analysis: apparatus reagents, procedures and some applications', Washington, D. C, [s.n. ], Agricultural Handbook, pp. 379.

Harrison, MT, Evans, JR, Dove, H \& Moore, AD, 2011, 'Dual-purpose cereals: can the relative influences of management and environment on crop recovery and grain yield be dissected?', Crop \& Pasture Science, vol. 62, pp. 930-946. lapar - Instituto Agronômico do Paraná. 'Cartas Climáticas do Paraná', 2000, versão 1.0, (formato digital, 1 CD).

Jobim, CC \& Nussio, LG, 2013, 'Princípios básicos da fermentação na ensilagem', In: Forragicultura: ciência, tecnologia e gestão de recursos forrageiros, Jaboticabal, Brandel, cap. 40, pp. 649-660.

Lehmen, RI, Fontanelli, RS, Fontanelli, RS \& Santos, HP, 2014, 'Rendimento, valor nutritivo e características fermentativas de silagens de cereais de inverno', Ciência Rural, vol. 44, n. 7, pp. 1180-1185.

McGoverin, CM, Snyders, F, Muller, N, Botes, W, Fox, G \& Manley, M, 2011 , 'A review of triticale uses and the effect of growth environment on grain quality', Journal of the Science Food and Agriculture, vol. 91, pp. 1155-1165.

Meinerz, GR, Olivo, CJ, Viégas, J, Nörnberg, JL, Agnolin, CA \& Scheibler, $R B, 2011$, 'Silagem de cereais de inverno submetidos ao manejo de duplo propósito', Revista Brasileira de Zootecnia, vol. 40, n. 10, pp. 2097-2104.

Nascimento Júnior, D, Vilela, HH, Sousa, BML \& Silveira, MCT, 2013, 'Fatores que afetam a qualidade de plantas forrageiras', In Forragicultura: ciência, tecnologia e gestão de recursos forrageiros, Jaboticabal, Brandel, cap. 27, pp. 409-424.

Nussio, LG, Campos, FP \& Lima, M.L.M, 2011 , 'Metabolismo de Carboidratos Estruturais, In: Nutrição de ruminantes, ed. 2, Jaboticabal, Funep, cap. 7, pp. 193-238.

Sas Institute, 2015, 'SAS/STAT user's guide statistics', ed. 4, Cary, North Caroline, pp. 943.

Silva, DJ \& Queiroz, AC, 2009, 'Análise de Alimentos, métodos químicos e biológicos', ed. 3 - $4^{a}$ reimpressão, Universidade Federal de Viçosa, pp. 235.

Taiz, L \& Zeiger, E, 2009, 'Plant physiology', ed. 4, Califórnia: The Benjamin/Cummings Publishings Company, Redwood, pp. 819.

Van Soest, PJ, Robertson, JB \& Lewis, BA, 1991, 'Methods for dietary fiber, neutral detergent fiber, and nonstarch polysaccharides in relation to animal nutrition', Journal of dairy Science, vol. 74, pp. 3583-3597. 